INT. J. REMOTE SENSING, 2000, VOL. 21, NO. 6 \& 7, 1093-1114

\title{
Land cover mapping of large areas from satellites: status and research priorities
}

\author{
J. CIHLAR \\ Canada Centre for Remote Sensing, Ottawa K1A 0Y7, Canada; \\ e-mail address: josef.cihlar@ccrs.nrcan.gc.ca
}

\begin{abstract}
Although land cover mapping is one of the earliest applications of remote sensing technology, routine mapping over large areas has only relatively recently come under consideration. This change has resulted from new information requirements as well as from new developments in remote sensing science and technology. In the near future, new data types will become available that will enable marked progress to be made in land cover mapping over large areas at a range of spatial resolutions. This paper is concerned with mapping strategies based on 'coarse' and 'fine' resolution satellite data as well as their combinations. The status of land cover mapping is discussed in relation to requirements, data sources and analysis methodologies -including pixel or scene compositing, radiometric corrections, classification and accuracy assessment. The overview sets the stage for identifying research priorities in data pre-processingand classification in relation to forthcoming improvements in data sources as well as new requirements for land cover information.
\end{abstract}

\section{Introduction and objective}

Land cover, i.e. the composition and characteristics of land surface elements, is key environmental information. It is important for many scientific, resource management and policy purposes and for a range of human activities. It is an important determinant of land use and thus of value of land to the society. Land cover varies at a range of spatial scales from local to global, and at temporal frequencies of days to millennia. As the need for environmental planning and management became important, an accompanying call for land cover information emerged in parallel.

Land cover mapping is a product of the development of remote sensing, initially through aerial photography (Colwell 1960). This is because 'viewing' large areas repeatedly is necessary for acquiring information about land cover. For the same reason, land cover mapping has been perhaps the most widely studied problem employing satellite data, beginning with Landsat 1 . However, most of the studies using 'fine' resolution data (i.e. $\preccurlyeq 20-100 \mathrm{~m}$ ) were methodological in nature, exploring various information extraction techniques and applying these over limited areas. Applications over large areas were hampered by the lack of suitable technology, an absence of a user community with a strong need for such information, a lack of appropriate analysis methodologies, and the cost of data. Thus, at the global level, land cover data sets compiled from ground surveys or various national sources (Mathews 1983, Olson et al. 1983) were, for a number of years, the major source of information. 
Partly in view of the above obstacles (data volumes, cost, etc.), since the late 1980s increased attention has been paid to the use of coarse resolution optical data, represented primarily by NOAA (National Oceanic and Atmospheric Administration) Advanced Very High Resolution Radiometer (AVHRR) images. These were initially available at $8 \mathrm{~km}$ resolution and later, through the initiative of the International Geosphere-Biosphere Programme (IGBP) (Townshend et al. 1994) and a project involving many AVHRR receiving stations (Eidenshink and Faundeen 1994), at the nominal resolution of $1 \mathrm{~km}$ for all land areas of the globe. Through these efforts, first satellite-based global land cover maps have already been produced (DeFries and Townshend 1994, DeFries et al. 1998, Hansen et al. 2000, Loveland et al. 2000).

For coarse as well as fine resolution data, the limiting factors described above are changing at the present time. The emergence of global environmental issues addressed by the IGBP (1990), the Framework Convention for Climate Change, the Kyoto Protocol, the Biodiversity Convention, global observing systems (GCOS 1997) and other international policy instruments have brought a new, critical requirement for land cover information at many scales, from landscape to global. Computer speed is no longer an obstacle to processing large volumes of data by a small team. The cost of data has gradually decreased (especially data for research purposes), and has changed fundamentally with the launch of Landsat 7. The launch of new satellite sensors such as Landsat 7 (http://landsat.gsfc.nasa.gov/), SPOT 4 VEGETATION (VGT) (Saint 1992), Moderate Resolution Imaging Spectroradiometer (MODIS) (Barnes et al. 1998, Salomonson et al. 1989, Running et al. 1994), Medium Resolution Imaging Spectrometer (MERIS) (http://envisat.estec.esa.nl/) and Global Imager (GLI) http://hdsn.eoc.nasda.go.jp/guide/guide/satellite/sendata/gli - e.html) with a systematic global acquisition strategy will inaugurate a new era in land remote sensing during which (i) high quality data sets will be available globally for land cover mapping applications and (ii) the remote sensing research community will be expected to deliver sound methodologies for generating land cover information products (as well as the first series of such products).

For the above reasons, the turn of the century is a milestone in land cover mapping, and the future will be unlike the past. It is thus appropriate to take a more detached view of the issues involved, main problem areas and important research directions for the next several years. This paper focuses on the methodologies for generating land cover information products over large areas. The significance of the methodologies is self-evident and their impact on the quality of the final products will be decisive. The paper considers the end-to-end process in preparing land cover maps and the types of algorithms and information extraction procedures. The discussion is limited to land cover mapping, i.e. periodic determination of land cover distribution over the entire area of interest (as opposed to land cover change), and to the use of multispectral optical data - the part of the electromagnetic spectrum found most useful for land cover mapping in research to date.

\section{Dimensions of the land cover mapping problem}

There are several important considerations that determine the characteristics of land cover information. 
(1) Purpose. Land cover information is obtained for numerous scientific, policy, planning or management purposes. Within each of these areas, a wide range of needs exists. For example, specific models of vegetation-atmosphere interactions require different types of land cover information (Dickinson et al. 1986, Sellers et al. 1996). Similarly, productivity models (Liu et al. 1997), hydrological models (Wigmosta et al. 1994), forest inventories (Magnussen 1997), land use inventories and planning as well as other biophysical resource inventories (Jennings 1995), and many other activities require land cover information.

(2) Thematic content. The information may be needed for few cover types (e.g. forest-non-forest); for all cover types and at the same (or varying) levels of detail; tailored to specific model requirements; or as continuous variables (e.g. percentage coniferous forest). The thematic content also has a strong effect on the frequency of land cover mapping.

(3) Scale. Over large areas, land cover information may be required locally (at specific sites, $\left.10^{0}-10^{3} \mathrm{~km}^{2}\right)$, at regional scales $\left(10^{4}-10^{6} \mathrm{~km}^{2}\right)$, or continental to global scales $\left(\succ 10^{6} \mathrm{~km}^{2}\right)$.

(4) Data. The quality and availability of remote sensing data limit the type and accuracy of information that may be extracted.

(5) Processing and analysis algorithms. The characteristics of algorithms employed at the various processing stages are of critical importance, as discussed in more detail below.

The purpose and thematic content help define the classes that must be differentiated in the land cover product, i.e. the mapping legend. The scale, together with the legend, determines the remote sensing data source appropriate to the mapping problem. Data and algorithms employed constrain the information that may be present in the final products. To limit the discussion that follows, it is assumed that the purpose of the land cover mapping is to produce information at regional to global scales $\left(\geq 10^{5} \mathrm{~km}^{2}\right)$ and for all cover types present (although not necessarily at the same level of thematic detail, e.g. a map could have more detailed classes for forest and less detailed for other types).

Since land cover changes over time, the temporal resolution is a critical consideration in choosing the appropriate data type. Figure 1 portrays the relationships between spatial resolution, temporal resolution and satellite data sources. The dotted line identifies the principal domain of interest to large-area land cover mapping employing satellite data. Such mapping is not required for very small areas or very frequently (i.e. the lower left part of the graph). Thus, the domain of interest spans the range between two extremes: 'coarse' resolution at frequent time intervals (lower right part of the plot), and 'fine' resolution at long intervals (upper left). It should be noted that the labels 'coarse' and 'fine' are relative and that each covers a range of resolutions; for example, 'coarse' is appropriate for AVHRR $8 \mathrm{~km}$ data but not for MODIS $250 \mathrm{~m}$ data. The terms are used in this paper for brevity to categorize a sensor but the qualification must be kept firmly in mind.

The range between the above extremes is a continuum accessible through satellite remote sensing techniques. Theoretically, the entire range could be covered using satellite data from the lower left corner of the range, i.e. data obtained very frequently and at a high spatial resolution. However, this is a practical impossibility at the present, and a cost-ineffective solution at any time because land cover does not 


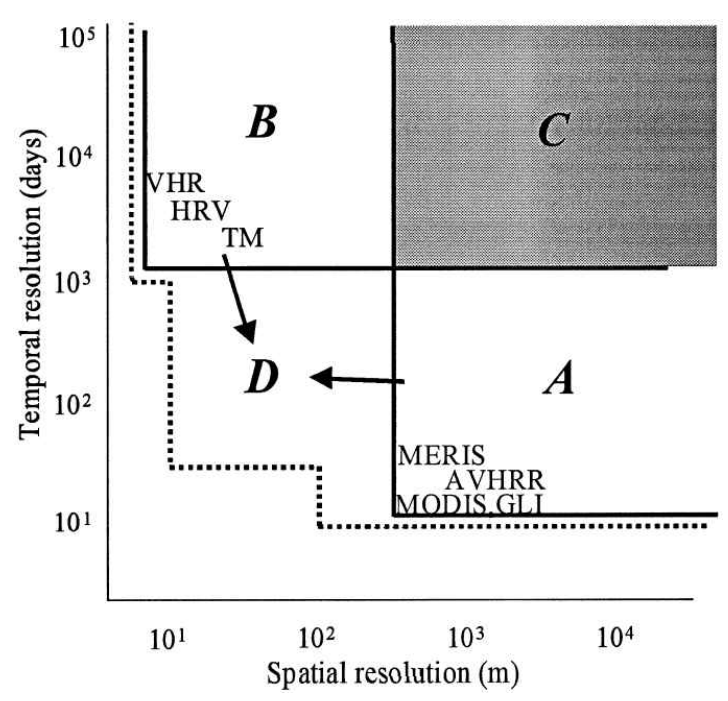

Figure 1. Land cover mapping requirements expressed in spatial and temporal resolutions. The acronyms represent current or future satellite sensors at both fine and coarse resolutions; VHR denotes future very high resolution sensors, now being prepared for launch by several private companies.

change rapidly enough in all places. Thus, a more realistic approach is to consider the range as consisting of discrete components.

Region A in figure 1 represents mapping with frequently obtained coarse resolution data. With such data it is possible to prepare higher level data sets through pixel compositing procedures (Holben 1986), thus allowing global land cover maps to be produced at short intervals. In region $\mathrm{B}$, fine resolution data are obtained relatively infrequently. Therefore, along with unavoidable cloud contamination and seasonal phenological effects, data sets suitable for land cover analysis can be compiled only over longer time periods. A coverage of large areas is thus produced through 'scene compositing', i.e. by mosaicking the individual images. Region $\mathrm{C}$ can utilize land cover products generated by methods in A or B. So far, the approach has been to employ A for mapping and B for training and/or validation (e.g. Cihlar and Beaubien 1998, DeFries et al. 1998, Hansen et al. 2000). Region D presents the greatest challenge, requiring frequent coverage at fine resolution. While this is not now realistically possible over large areas, it should be feasible to synergistically combine data and products from parts $\mathrm{A}$ and $\mathrm{B}$, thus obtaining effectively the same information; this is discussed in more detail in §3.3. Figure 1 also shows the approximate positions of some important satellite sensors.

So far, satellite-based large-area mapping has been mostly performed in region A (figure 1) because of the availability of data and the manageable computational demands. Land cover maps at $8 \mathrm{~km}$ resolution or coarser were prepared from AVHRR Global Area Coverage (GAC) data (DeFries and Townshend 1994, DeFries et al. 1998). Maps for landscape regions (e.g. Cihlar et al. 1997a,b, Steayert et al. 1997, Laporte et al. 1998) or larger areas (Loveland et al. 1991, 1995, Cihlar and Beaubien 1998) have been produced in recent years with $1 \mathrm{~km}$ AVHRR data. With the availability of the global AVHRR $1 \mathrm{~km}$ data set (Eidenshink and Faundeen 1994), intensive activities led to global products at the same resolution (Loveland 
and Belward 1997, Hansen et al. 2000, Loveland et al. 2000). So far, region A maps have been produced infrequently. However, the same techniques can be used to generate land cover maps at shorter time intervals, as short as the minimum compositing period resulting in a usable data set. For region B, the work so far has been limited mostly to studies over small areas, such as a Landsat scene or less. Among the exceptions is the US GAP program (Jennings 1995), through which maps over entire states have been produced (Driese et al. 1997, Homer et al. 1997), humid tropical deforestation studies, and other experimental products prepared through scene compositing (Guindon 1995, Homer et al. 1997, Beaubien et al. 1999, Vogelmann et al. 1998). Apart from some methodological studies (e.g. Moody and Woodcock 1996, Cihlar et al. 1998c), little work on region D has been carried out.

\section{Analysis methods}

In principle, land cover mapping from satellite data is straightforward and consists of four steps: data acquisition, pre-processing, analysis/classification and product generation and documentation. However, details of these steps differ fundamentally between regions $\mathrm{A}$ and $\mathrm{B}$ of figure 1 . In $\mathrm{A}$, the acquisition is frequent (every one or very few days), and pre-processing includes image compositing by choosing individual pixels from a period of several days, typically 5-10. Consequently, one can obtain a nominally cloud-free product for every compositing period but at the cost of increased image noise. In part B, images are obtained so infrequently (e.g. $>2$ weeks) that the pixel compositing approach is not viable and scene compositing must instead be employed. These differences have a strong impact on the pre-processing and classification techniques.

\subsection{Pre-processing}

The objective of this step is to present the data in a format from which accurate land cover information can be extracted. In principle, it entails geometric and radiometric corrections (figure 2). Geometric corrections will not be discussed here as they have already been worked out for both coarse (e.g. Cracknell and Paithoonwattanakij 1989, Emery et al. 1989, Roberston et al. 1992, Nishihama et al. 1997 ) and fine (Friedmann 1981) resolution satellite data.

\subsubsection{Coarse resolution data}

In the past, some classification projects employing coarse resolution data were carried out with single-date, relatively cloud-free images (e.g. Pokrant 1991, Beaubien and Simard 1993). However, this approach is fundamentally limited because the probability of cloud-free scenes decreases as the area covered by one scene increases. It is thus very difficult to obtain useful images for land cover mapping, especially if the eligible time interval is short. Furthermore, such images contain systematic errors due to atmospheric effects (as a function of the path length) as well as monotonically changing spatial resolution for most coarse resolution sensors. Their classification is therefore difficult and requires interactive fine tuning for each input scene used, as well as post-classification operations to reconcile differences between adjacent scenes and thus ensure consistency across the mapped area. For these reasons, research in recent years has emphasised the use of image composites.

In a compositing process, the image product is prepared so as to contain, as far as possible, information about the land surface itself. Since a large fraction of the pixels typically contain clouds, the main objective of the procedure is to select the 


\begin{tabular}{|c|c|c|}
\hline OPERATION & $\begin{array}{c}\text { FINE } \\
\text { RESOLUTION }\end{array}$ & $\begin{array}{c}\text { COARSE } \\
\text { RESOLUTION }\end{array}$ \\
\hline $\begin{array}{l}\text { GEOMETRIC } \\
\text { CORRECTIONS }\end{array}$ & & \\
\hline COMPOSITING & $\begin{array}{c}\text { BY SCENE } \\
\text { (CLEAR-SKY ONLY) }\end{array}$ & $\begin{array}{l}\text { BY PIXEL } \\
\text { (ALL DATA) }\end{array}$ \\
\hline $\begin{array}{l}\text { RADIOMETRIC } \\
\text { CORRECTIONS }\end{array}$ & $\begin{array}{l}\text { - ATMOSPHERIC } \\
\text { • RADIOMETRIC } \\
\text { ADJUSTMENTS }\end{array}$ & $\begin{array}{l}\text { - ATMOSPHERIC } \\
\text { - BIDIRECTIONAL } \\
\text { - RESIDUAL } \\
\text { CONTAMINATION }\end{array}$ \\
\hline $\begin{array}{l}\text { CLASSIFIC- } \\
\text { ATION }\end{array}$ & CASE I & CASE II \\
\hline $\begin{array}{l}\text { ACCURACY } \\
\text { ASSESSMENT }\end{array}$ & & \\
\hline
\end{tabular}

Figure 2. Major steps in extracting land cover information using satellite data at fine and coarse resolutions. See text for discussion.

most cloud-free measurement from those available for a given pixel of the composite image. At present, the selection is most often based on the maximum value of the Normalized Difference Vegetation Index (NDVI) (Holben 1986). Advantages of the NDVI criterion include high sensitivity to atmospheric contamination, ease of computation and wide acceptance in previous studies, thus creating a de facto standard. Others have shown that maximum NDVI composites contain artefacts caused by the behaviour of the NDVI itself (e.g. Goward et al. 1991, Cihlar et al. 1994 a,b, Qi and Kerr 1994). Nevertheless, the alternatives proposed so far have their own disadvantages and, furthermore, the main drawback, i.e. a tendency to select pixels with forward-scattering geometry, can be overcome through bidirectional reflectance corrections (e.g. Leroy 1994, Li et al. 1996, Ba et al. 1997, Cihlar et al. 1997b). This is not to say that the compositing problem has been solved (see $\$ 4.1$ ).

The pixel compositing approach yields nominally cloud-free composites every few days, thus providing a potentially large data set for land cover classification. However, in this form the data are far from adequate for such a purpose. This is because the composites have built-in noise from the varying satellite sensing geometry and from residual clouds or variable atmospheric properties (water vapour, aerosols, ozone). These effects are normally present between adjacent composite pixels and can lead to large radiometric differences for the same land cover type, thus causing classification errors. They also have a strong impact on the consistency of satellite data, both within and among years. For example, Cihlar et al. (1998a) found that 
depending on the measurement of interest (AVHRR channel 1,2 or NDVI) and land cover type, the most important correction is the removal of contaminated pixels, atmospheric correction, or correction for bidirectional reflectance effects caused by differences in the source-target-sensor geometry. Thus, further pre-processing operations are necessary.

The degree of corrections following compositing varies among investigations. Atmospheric corrections are frequently carried out (e.g. Eidenshink and Faundeen 1994, James and Kalluri 1994, Cihlar et al. 1997b), although nominal/climatological values of some critical parameters are typically used or their effect is ignored (e.g. aerosol). While the nominal corrections account for systematic effects such as Rayleigh scattering, they are incapable of discerning pixel-specific atmospheric contamination caused by translucent or small (subpixel) clouds, haze, or snow patches. These effects are difficult to detect because present satellite data have insufficient spectral information (thus limiting cloud detection options based on spectral, pixelbased criteria) and because the use of spatial context is even more limited due to the inherent heterogeneity of land cover (especially with decreasing pixel size). Other possibilities thus need to be pursued (Gutman et al. 1994). Use of the temporal dimension is one option (Viovy et al. 1992, Los et al. 1994, Cihlar and Howarth 1994, Sellers et al. 1994). Sellers et al. (1994) used the NDVI temporal trajectory to flag contaminated pixels and Cihlar (1996) extended this approach in CECANT (Cloud Elimination from Composites using Albedo and NDVI Trend). Since the detection is NDVI-based, it can identify the above sources of noise because they tend to decrease the measured NDVI (compared to the 'expected value' for that pixel and compositing period). CECANT requires that data for the entire growing season be available so that the NDVI curve can be modelled. However, it is also applicable to new (current year) data provided that comparable full-season data are available for a previous year and some degradation of performance can be traded for timeliness (Cihlar et al. 1999).

Bidirectional corrections are possible but have not yet been frequently implemented because of the perceived complexity of the problem. Furthermore, bidirectional corrections require satellite measurements at different viewing geometries with the surface conditions remaining constant to maximize the accuracy of the inversion procedure (e.g. Barnsley et al. 1994). Such measurements are generally not available and this approach may become practically feasible only after the launch of EOS when the bidirectional space is sampled simultaneously by MODIS (Moderate Resolution Imaging Spectroradiometer) and MISR (Multi-Angle Imaging Spectroradiometer) (Martonchik et al. 1998). Another option is to correct satellite data to a standard viewing geometry (Gutman 1994, Sellers et al. 1994). This option requires knowledge of which model to apply to each pixel to be corrected. Typically, the models are derived for individual cover types, and land cover thus becomes a pre-requisite to using this approach. The procedure might become somewhat circular, except that the bidirectional dependence does not appear highly cover type-specific and few types need to be differentiated ( $\mathrm{Wu}$ et al. 1995). Furthermore, the coefficients for these functions need not be known a priori but may be derived from the data set itself (Chen and Cihlar 1997, Cihlar et al. 1997b). This means that a simple land cover classification (e.g. an existing one or one based on NDVI only which is less sensitive to bidirectional effects) could be used in the correction of satellite data, the latter to be used for a more detailed differentiation of the various cover types or conditions. 


\subsubsection{Fine resolution data}

In the past, most land cover studies employing high resolution data were carried out with single images (hereafter called 'scenes'), parts of scenes or an assembly of such scenes from different areas. In these cases, radiometric consistency was not an issue because the classification could be optimized individually for each scene. When classifying a scene composite (i.e. a mosaic of scenes), the situation is more complicated. In principle, two options are possible (figure 2). First (case I), one can classify each scene separately and subsequently reconcile the classes across the mosaic. Another approach (case II) is to assemble a mosaic of scenes for the entire area, establish radiometric uniformity across the mosaic, and then classify it as one entity.

In case I, each scene is treated as a separate data set to be classified, using ancillary data that are appropriate for the classification procedure employed. It is thus slow and labour-intensive. The reconciliation of classification across the boundaries between adjacent scenes can be difficult and may require changes in the classification(s) or labelling to be carried out within individual scenes. Even with these measures, discontinuities between scenes are not necessarily removed if significant radiometric differences were present at the outset. Thus, even with much intervention by the analyst, post-classification reconciliation does not guarantee success. On the other hand, procedure I is highly flexible and can cope with various limitations of the input data. It has thus been used extensively in the past and good results have been reported (Pokrant 1991, Driese et al. 1997).

Because of the infrequent satellite revisits, the compositing of fine resolution data over large areas (case II) employs entire scenes, as opposed to individual pixels in the coarse resolution data. Thus, although radiometric noise is still present, it takes on different forms. First, atmospheric contamination is less limiting because only mostly cloud- and haze-free scenes (preferably $<10 \%$ ) are used for this purpose. Second, bidirectional problems are much less severe, particularly in the case of nadirlooking sensors with a narrow field of view such as the Landsat Thematic Mapper (TM) or Satellite Probatoire d'Observation de la Terre High Resolution Visible Imaging System (SPOT HRV) in nadir mode. Solar zenith angle corrections are thus the main ones to consider.

A substantial amount of research has been carried out in the area of radiometric equalization across scene composites. Typically, the algorithms utilize overlaps between adjacent scenes to establish the correction factors. These corrections have been carried out interactively (e.g. Beaubien et al. 1999) or they can be automated (Chavez 1988, 1989, Schott et al. 1988, Elvidge et al. 1995, Atzberger 1996, Yuan and Elvidge 1996, Guindon 1997). However, reconciling adjacent scenes may not be sufficient in larger scene composites. This is because the residual errors accumulate in a different manner, depending on the order of scenes to be corrected (Guindon 1997). Also, the sequence of corrections is not likely to achieve closure if done unidirectionally, i.e. radiometric values for one cover type may differ between the first and the last scene included in the composite. Therefore, an overall adjustment within the scene composite is preferable, in which the inconsistencies and radiometric differences are balanced to an overall optimum. This is conceptually similar to block adjustment employed in photogrammetry, and can be implemented for scene compositing purposes (e.g. Guindon 1995, PCI 1998). With such adjustments, the radiometric errors are minimized across the composite, based on the magnitude of the differences detected in the overlapping areas. These differences can conveniently be detected using overlaps with adjacent scenes or orbits. Because of the scale 
relationships between scene size and the size of atmospheric high-pressure areas, adjacent scenes along the orbit often have similar cloud contamination.

Even in radiometrically corrected scene composites, some noise will remain. The most important sources are local atmospheric effects such as haze, smoke or cumulus clouds in an otherwise clear-sky scene. Small but potentially significant bidirectional reflectance effects may also be present (Staenz et al. 1984). For example, Guindon (1997) observed differences of 1-5 digital levels between forescatter and backscatter directions in Landsat Multispectral Scanner (MSS) scenes; such differences could lead to classification discontinuities between adjacent scenes. These residual effects must be dealt with in the classification process.

In addition to purely radiometric noise, the uniformity is also affected by phenological differences among scenes that are more difficult to address. Potential solutions include enlarging the window during which acceptable data are acquired, usually by adding years from which data may be used; using data from other similar sensors; or attempting a 'phenological correction' based on seasonal trajectories established for similar targets. Such corrections would be required prior to scene compositing.

The use of scenes from various sensors in a composite has not yet been explored. In principle, it requires pre-processing the data from the added sensor to resemble the initial one, both spatially and spectrally. Spatial resolution presumes resampling to the same pixel size - a routine operation. Spectral adjustment is conceptually more difficult, and its feasibility will depend on the differences between the two sensors and the spectral characteristics of the targets in the imaged scene. The solution is easiest when the added sensor has more than one spectral band where the initial sensor has only one (e.g. Li and Leighton 1992). The inverse situation has no satisfactory solution and may render the added data set unsuitable.

It should be noted that the last two options (phenological correction and compositing scenes from various sensors) will also add radiometric noise of their own. Some form of between-scene reconciliation is therefore likely to be required in many cases. This, and the inevitable residual noise in the scene composite suggest that while the case II application may be the preferred solution, in practice it may often have to be supplemented by case I to obtain quality land cover maps.

\subsection{Classification}

Land cover information that can be gleaned from satellite images is the spectral and spatial attributes of individual cover types. There are some differences between coarse and fine resolution data, mainly in the relative importance of these two kinds of attributes. Because of the reduced resolution, the spectral dimension is the most important source of cover type information in coarse resolution images. For fine resolution data, the relative importance of the spatial dimension is higher, although the spectral content still dominates in most cases. In the following discussion, no distinction is therefore made between the two data types.

Numerical techniques for satellite image classification have a long tradition, dating back to at least the early 1970s. Two types of approaches have evolved and, in spite of recent developments, have remained as the basic options. They differ in the assumptions made about the knowledge of the scene to be classified. In supervised classification, a priori knowledge of all cover types to be mapped within the classified scene is assumed. This knowledge is used to define signatures of the classes of interest, to be applied to the entire scene. In unsupervised classification, no prior information 
about the land cover types or their distribution is required. Unsupervised classification methods divide the scene into more or less pure spectral clusters, typically constrained by pre-defined parameters characterizing the statistical properties of these clusters and the relationships among adjacent clusters. The assignment of land cover labels to individual spectral clusters is made subsequently on the basis of ground information, obtained in the locations indicated by the resulting clusters. In recent years, numerous variants of these two basic classification methods have been developed. These include decision trees (Hansen et al. 1996); neural networks (Carpenter et al. 1997, Foody et al. 1997, Bischof and Leonardins 1998, Yool 1998 ), fuzzy classification (Foody 1996, 1998, Mannan et al. 1998) and mixture modelling (van der Meer 1995) for supervised classification; and classification by progressive generalization (Cihlar et al. 1998e), classification through enhancement (Beaubien et al. 1999), and post-processing adjustments (Lark 1995 a, b) for unsupervised techniques.

It seems evident that when one knows what classes are desired and where they occur (at least as a sample), supervised classification strategies are preferable. However, over large areas the distribution of classes is not known a priori. This is compounded by the spatial trends in spectral signatures, resulting in the well known signature extension problem. These complexities render sample selection very difficult and often arbitrary. Thus, where spatial distribution information is not available, e.g. when mapping a large area previously not well known, unsupervised classification is arguably the better strategy (e.g. Achard and Estreguil 1995, Cihlar and Beaubien 1998 ), although a supervised method has also been used in such case (Hansen et al. 2000 ). Unsupervised classification provides more comprehensive information on the spectral characteristics of the area, presents spectrally pure clusters for the labelling step, and gives the opportunity to the analyst to group similar clusters into a smaller number of land cover classes. Perhaps the major problem with unsupervised classification is the effect of controlled parameters (e.g. number of clusters, allowable dispersion around a cluster mean) since, for the same data set, changes in these can produce different final clusters. A recent way of circumventing this limitation has been to produce a large number of clusters, typically 100-400 (Kelly and White 1993, Driese et al. 1997, Homer et al. 1997, Cihlar and Beaubien 1998, Cihlar et al. 1998e, Vogelmann et al. 1998). The large number of clusters is then reduced by well defined merging steps. The merging procedure can be based on statistical measures (i.e. again unsupervised), or can be carried out interactively by the analyst (e.g. figure 3). Given the large number of clusters in relation to the small number of resulting land cover types, the impact of control parameters on the final product is diminished in this case. Another important limitation of unsupervised classification is the potential mismatch between spectral clusters and thematic classes. The hyperclustering approach also mitigates this problem, but additional steps may be necessary (Lark 1995b). Independent ground information is required by both the supervised and unsupervised method. The important advantage of the latter is that concerns about the location and representativeness of the ground data are much reduced because the clusters are homogenous by definition.

While most classification strategies have focused on the use of the spectral dimension, the spatial domain also contains important information, especially in fine resolution data. Although numerous algorithms have been developed to quantify spatial relations within images such as texture (Gong et al. 1992), segment homogeneity (Kartikeyan et al. 1998 and references therein) and various others, the spatial 


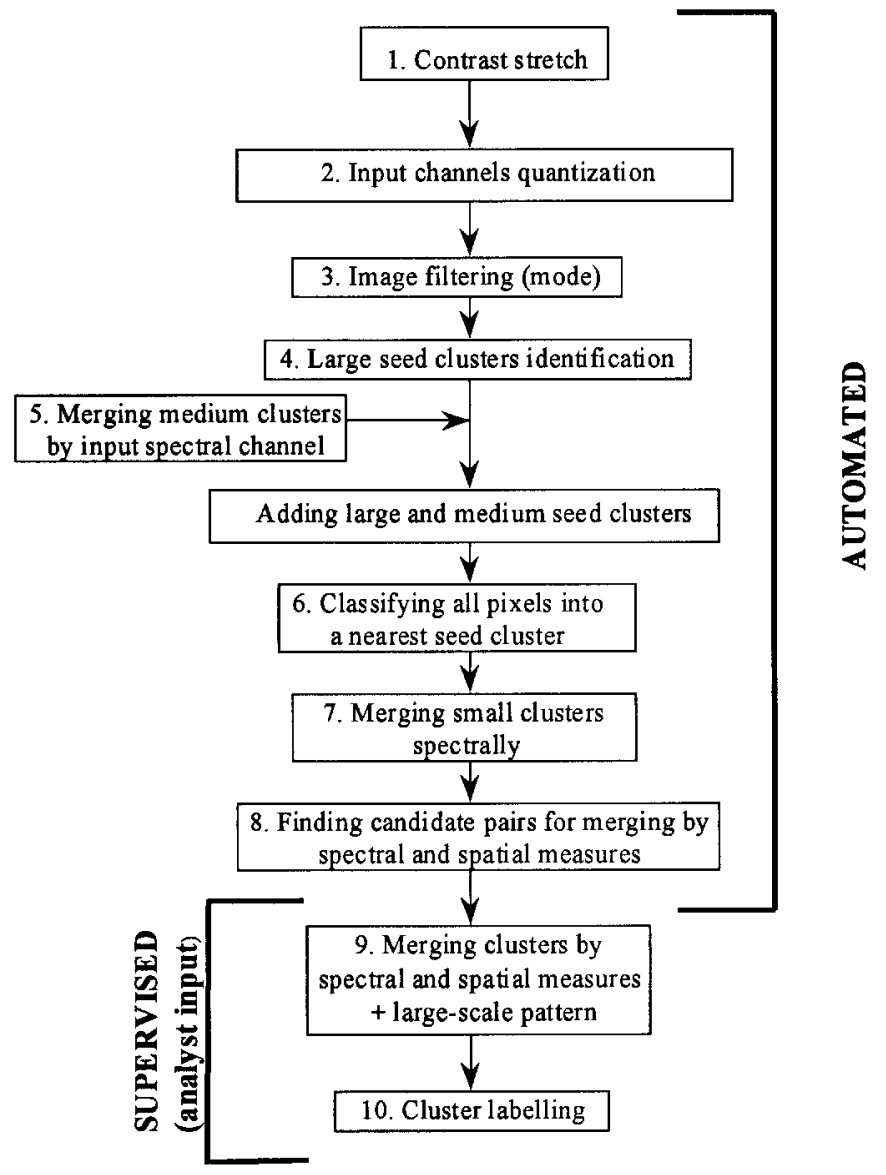

Figure 3. Flowchart for Classification by Progressive Generalization (CPG, Cihlar et al. 1998e). In this unsupervised classification, steps $1-8$ can be carried out in an automated mode but steps 9-10 require analyst's input. CPG assumes that any of the initial spectral values might represent a significant land cover class; the task is therefore to optimally group these values into a small number of final clusters. Steps 1-3 reduce the number of spectral combinations, without visually degrading the input image; steps 4-5 identify important clusters; and steps 7-9 allow merging of increasingly dissimilar clusters using spectral and spatial similarity measures.

dimension has not been used effectively in image classification so far. Spatial measures can be employed in supervised or unsupervised classification as additional channels, in unsupervised classification for cluster merging, as a pre-classifying step resulting in homogenous patches (per-field classifiers), and in other ways. Given the contribution that spatial attributes can make to land cover classification, their increased use is most desirable. Recent interest in an effective use of spatial and spectral information (Shimabukuro et al. 1997, Kartikeyan et al. 1998) is therefore encouraging.

An important consideration in land cover classification is consistency and reproducibility. That is, the same result should be obtained by various analysts given the same input data or ideally, even different input data over the same area. In practice, this means that as much as possible of the analysis should be done with objective, analyst-independent procedures. On the other hand, the analyst cannot be entirely 
excluded from the process because any classification is a human construct, imposing an artificial scheme on the natural world. One way of dealing with this dichotomy is to separate the tasks into distinct phases. For example, Cihlar et al. (1998e) described 'classification by progressive generalization', a non-iterative unsupervised classification procedure in which the selection of training samples, classification and initial merging of clusters are automated and thus fully reproducible (figure 3 ). In the last stage preceding labelling, the analyst is presented with suggestions for merging the remaining clusters but the decision is his/hers. The suggested merging is based on both spectral and spatial relations between the remaining cluster pairs. In this way, the number of clusters can be reduced to a few dozen (typically 70-120 in boreal ecosystems) without the need for ground information.

\subsection{Map frequently and at high spatial resolution?}

Region D in figure 1 represents land cover mapping applications at high spatial resolution and for short time intervals. Over large areas, such applications are rare if any, at the present time. High resolution satellite data are routinely employed over large areas, e.g. for annual crop assessment (de Boissezon et al. 1993), but in a sampling mode. The minimum required temporal frequency for land cover mapping at present appears to be about 5 years (Ahern et al. 1998, GCOS 1997). Nevertheless, it is desirable to know about the changes in land cover composition, though not the location of these changes for policy purposes, to satisfy reporting requirements, to assess the impact of management measures, or for other reasons. Thus, the question arises: can requirements in region $\mathrm{D}$ be met by a combination of full coarse resolution coverage and a sample of high resolution data? Importantly, such an approach could also meet some of the high resolution coverage (region B in figure 1) but at a considerably lower cost.

Numerous studies have demonstrated the effectiveness of combining coarse and fine resolution images in estimating the area of one class, e.g. forests (Mayaux and Lambin 1995, 1997, DeFries et al. 1997, Mayaux et al. 1998). When dealing with many classes, the methodological considerations are more complex (Walsh and Burk 1993, Moody and Woodcock 1996). Given a coarse resolution land cover map for an area (domain), it may be used to stratify the domain into units with a similar composition, then sample these with high resolution data. The challenge is in finding appropriate stratification and sampling framework that uses the domain coverage effectively. Cihlar et al. (1998b) proposed a methodology based on a domain coverage by coarse resolution data and a potential sample of high resolution images (full frame), as specified by the path/row grid for high resolution sensors such as Landsat TM (NASA 1982). With these two inputs, one can determine land cover composition for both the domain and each potential image/sample unit, and thus quantify the similarity between the two. Cihlar et al. (1998b) chose Euclidean distance for composition and contagion index (O’Neill et al. 1988) for fragmentation, but various other measures are possible. They then postulated that the optimum sample is that which most closely approximates the composition of the domain land cover. In this scheme, the high resolution sample images are selected, one at a time, on the basis of their ability to bring the composition of the sample close to that of the domain. In testing the effectiveness of this scheme to assess the proportions of land cover types over an $136432 \mathrm{~km}^{2}$ area, Cihlar et al. (1998c) found that this selection method converges rapidly on the actual area of individual land classes. The selected sample was 1.5 to 2.1 times more effective in reducing the relative error than a random sample of the 
same size, allowing one to obtain a comparable (higher) precision at a lower (the same) cost. It should be noted that once the composition of the coarse resolution land cover classes is determined in this manner, the approximate spatial distribution of individual classes at fine resolution is also known since it can be expressed as fraction of each coarse resolution pixel; thus, a map for region D (figure 1) can also be produced, although it will not have the pixel-specific accuracy at the fine spatial resolution.

\subsection{Accuracy assessment}

No land cover classification project would be complete without an accuracy assessment. It may well be that concern about the accuracy of land cover maps did not exist before the advent of satellite-based methods and photo interpretation-based maps were assumed 100\% accurate (this is still often the case, e.g. in forest inventories). The need for accuracy assessment initially arose as part of algorithm development, and it was extended into an important tool for users of land cover products. Many papers have been written on the methods of accuracy assessment, and various accuracy measures have been defined (e.g. Hord and Brooner 1976, Thomas and Allcock 1984, Rosenfield and Fitzpatrick-Lins 1986, Congalton 1991, Hammond and Verbyla 1996, Edwards et al. 1998). At this point, the principles of accuracy assessment are well known. The ideal requirements are based on sampling theory, but practical considerations regarding access, resources, etc. constrain the 'desirable'. There are also methodological difficulties with respect to spatial resolution, mixed pixels in coarse resolution satellite data being of special relevance. At the coarse resolution, many pixels contain a mixture of cover types even in a fairly general classification scheme such as land versus water, thus creating a difficulty in deciding on the correctness of the assigned label. An obvious approach is to assign the pixel to the single largest cover type within the pixel (e.g. Cihlar et al. 1996, Hansen et al. 2000). This can be accomplished with the aid of fine resolution maps where these are available. However, it is questionable when the dominant land cover type covers much less than $50 \%$ of the pixel. Furthermore, since the high resolution maps have errors (as do maps obtained through airborne techniques such as aerial photographs, airborne video, etc.), a definitive accuracy assessment needs to contain 'ground truth' as part of the sampling design (e.g. Magnussen 1997).

In addition to purely methodological considerations, accuracy assessment tends to be strongly constrained by the resources available. The acquisition of verification data can be expensive, especially if a statistical design is rigorously followed, access is difficult, etc. Within these constraints, however, creative solutions are possible. For example, Kalkhan et al. (1998) described the combined use of air photo interpretation and a sample of ground data to assess the accuracy of Landsat-derived proportions of land cover types, with 200 samples at the first stage and only 25 among these described in the field. To complicate matters further, ground truth may not necessarily be correct either; its errors can be due to incorrectly specified location, very small land cover patches being used, the inability of the surveyor to see a larger area of the surface, inconsistencies in labelling, etc. Thus, in practice, accuracy assessment is likely to remain a matter of compromise between the ideal and the affordable, or 'A balance between what is statistically sound and what is practically attainable must be found...' (Congalton 1996, p. 124). 


\section{Research needs and opportunities}

In general, research needs and opportunities are related to present and upcoming information requirements over large areas, and the expected evolution in the relevant data and technological tools. In all these areas, land cover mapping applications will receive a strong boost due to: increased demand for information because of concerns about climate change and sustainable development; several new sensors designed with land cover mapping as an important application; and the continuing rapid growth in computing technology.

\subsection{Pre-processing}

Assuming that the range of land cover mapping requirements is represented by all four areas A-D (figure 1), the focus needs to be maintained on improving the methods for optimally using data from new coarse and fine resolution sensors. For coarse resolution sensors, this means improved methods for image corrections, especially atmospheric, sensing geometry and pixel contamination. The objective should be to produce a cloud-free composite image which has radiometric properties of a single-date, fixed geometry image obtained during the same period. The availability of high quality, calibrated data from MODIS, MERIS, VGT and GLI will make major improvements possible. This goal cannot be fully achieved for most sensors because of the changing spatial resolution with the viewing angle, although in some cases (e.g. SPOT VGT, Saint 1992) the resolution is view angle-independent. Innovative ways must be found to define and implement robust, accurate and automated algorithms for the generation of superior composite products. Newly available tools are calibrated data, improved spectral coverage (new as well as sharpened bands), and the considerable progress made in recent years in defining algorithms for atmospheric parameters extraction, bidirectional corrections, etc. Although the ultimate solution is an accurate detection of contaminated pixels and retention of all remaining ones with the associated angular information, compositing will be a necessary pre-processing step for land cover classification in the foreseeable future. Further work on compositing algorithms thus appears warranted, with the currently ubiquitous maximum NDVI criterion used as the basis for comparison.

In the case of fine resolution sensors, the main pre-processing need is for accurate and robust scene compositing. This implies accurate sensor calibration and atmospheric corrections, although these measures alone are not sufficient. Local atmospheric effects (thin clouds, haze, smoke), subtle bidirectional effects, or small phenological changes may yield to algorithmic solutions but they pose a significant challenge. Much more research is needed on the preparation of large-area scene composites, to work out the theoretical and practical problems of dealing with residual atmospheric, phenological and other types of noise. Research is also required on compositing images from different sensors, with the objective of producing mosaics of the same consistency as from one sensor. Once these techniques are developed sufficiently well to be automated, it should be possible to produce 'virtual scene composites', on the basis of which the user could routinely order data set(s) covering the geographic area of interest over the specified compositing period(s). Of course, if any of the above radiometric differences within the composite are not resolved at the pre-processing stage, they must be dealt with during classification.

\subsection{Classification}

Cihlar et al. (1998e) proposed that classification algorithms should ideally satisfy the following requirements: accuracy; reproducibility by others given the same input 
data; robustness (not sensitive to small changes in the input data); ability to fully exploit the information content of the data; applicability uniformly over the whole domain of interest; and objectiveness (not dependent on the analyst's decisions). Many present digital image classification methods do not meet these criteria, and none meets them completely. Yet, such criteria are fundamental to a scientifically based methodology. Some of the implications are briefly discussed below.

The interest and innovation in image classification methods has continued in recent years, as has the 'creative tension' between supervised and unsupervised approaches and their variants. This will undoubtedly continue, and it is a healthy and beneficial process which should lead to better algorithms. Work is needed especially in mitigating the limitations of the two basic approaches, supervised and unsupervised, stemming from the fundamental assumptions (Chuvieco and Congalton, 1988, Bauer et al. 1994, Lillesand 1996).

Although initially digital spectral values were the main input for classification, various types of data have been considered more recently, either during classification (DeFries et al. 1995) or at the labelling stage (Brown et al. 1993). This will be a continuing requirement, especially as the number of spectral bands increases and new bands may prove to carry unique information content (e.g. Eva et al. 1998).

There is a strong need to make better use of spatial information. After all, useful land cover maps were produced from this attribute alone before the advent of colour photography and digital classification. In addition to texture (which is easily computed but not necessarily an informative attribute), more attention needs to be given to other measures such as pattern, shape and context (Rabben 1960). Another problem is in optimally and synergistically combining spectral and spatial elements, using one to improve the quantity and quality of land cover information obtained from the other.

A special challenge in image classification is to isolate, and minimize if possible, the role of the analyst in the classification. This is important because reproducibility is a fundamental requirement for any method or product. When the analyst's input is distributed throughout the classification procedure, the result is not reproducible. On the other hand, as long as discrete (thus artificial to some degree) classification legends continue to be used, the analyst's role cannot be eliminated because the class distinctions do not necessarily correspond to equivalent distinctions in reality. However, it is possible to assign a more precise role to the analyst, and to limit his input to specific portions of the classification procedure. This will improve the reproducibility of the entire process, and will highlight the impact of the analyst's decisions. A range of options are possible here. For example, in fuzzy classification approaches, the analyst's role can be reduced to defining the acceptable fractional composition of each class in terms of individual components.

A further step in reducing the subjective component in classifications is to first prepare specific biophysical products with continuous variables. For example, Running et al. (1995) proposed that three variables (permanence of above ground live biomass, leaf area index, leaf longevity) characterize vegetated land cover. If such separate products can be derived from satellite data, individual users can construct an optimized classification legend for all the land cover types or conditions present in the area to meet their specific objective. This does not eliminate need for classifications but renders the whole process more useful because of a better fit of the classification with specific user needs. The challenges here stem from the fact that 'land cover' can imply various characteristics, not all easily translated into biophysical 
variables that can be derived from satellite data (e.g. the hydrological regime). Nevertheless, this area needs to be pursued because of the potential gains in the utility of satellite-derived information products. The work done so far on two or a few classes (e.g. Iverson et al. 1994, Zhu and Evans 1994, DeFries et al. 1997) needs to be extended to multiple cover types. Data from other sensors, such as satellite radars or lidars (Dubayah et al. 1997) should be useful in developing the fields of continuous variables.

Although for scene composites (Region B, figure 1) the desirable approach is classifying the entire mosaic as one entity, it is very likely that data limitations will make this impossible in many cases. Local adjustments will thus be needed to achieve optimum results. The locations of these should be evident based on input image quality, but algorithms will be required to make this process reproducible and consistent.

Further research is needed on the synergistic use of data from coarse and fine resolution sensors to span the entire range of requirements represented in figure 1. Region D is the most demanding, with high spatial and temporal resolutions. It is also an area where large progress can be expected, given the resolution of new sensors around $300 \mathrm{~m}$.

\section{Concluding remarks}

In the last 5-10 years, land cover mapping from satellites has come of age. Although research on various issues regarding data pre-processing, classification and accuracy assessment has continued, new and unique data land cover products have been generated which could not be produced by earlier techniques. This is only a start, however. Many of the technical limitations hampering further improvements in land cover mapping will be removed in the next few years, especially in the quality of satellite data (improved calibration, spatial and spectral resolution, spectral coverage, geolocation accuracy) and the computing capability, founded on the accumulated knowledge and experience in the use of digital analysis methods. Thus, Earth observations have the potential to respond to the growing and urgent demand for timely and accurate land cover information over large areas. The fulfilment of the promise will require strong, ongoing research activities as well as new initiatives in the production of land cover maps. The research agenda needs to address the best ways of taking advantage of the new capabilities and, importantly, the ways of resolving problems identified during the production of the land cover maps over large areas.

\section{References}

Achard, F., and Estreguil, C., 1995, Forest classification of southeast Asia using NOAA AVHRR data. Remote Sensing of Environment, 54, 198-208.

Ahern, F. J., Janetos, A. C., and Langham, E., 1998, Global Observation of Forest Cover: a CEOS' Integrated Observing Strategy. Proceedings of 27th International Symposium on Remote Sensing of Environment, Tromsø, Norway, June 8-12 1998 (Norway: International Symposium on Remote Sensing of Environment), pp. 103-105.

AtzBerger, C. G., 1996, The spectral correlation concept: an effective new image-based atmospheric correction methodology over land areas. In Progress in Environmental Remote Sensing Research and Applications, edited by A. Parlow (Rotterdam: Balkema), pp. $125-132$.

Ba, M. B., Dedieu, G., Kerr, Y. H., Nicholson, S. E., and LecocQ, J., 1997, Reduction of bidirectional effects in NOAA-AVHRR data acquired during the HAPEX-Sahel experiment. Journal of Hydrology, 188-189, 725-748. 
Barnes, W. L., Pagano, T. S., and Salomonson, V. V., 1998, Prelaunch characteristics of the Moderate Resolution Imaging Spectrometer (MODIS) on EOS-AM/1. IEEE Transactions on Geoscience and Remote Sensing, 36, 1088-1100.

Barnsley, M. J., Strahler, A. H., Morris, K. P., and Muller, J.-P., 1994, Sampling the surface bidirectional reflectance distribution function(BRDF): 1. Evaluation of current and future sensors. Remote Sensing Reviews, 8, 271-311.

Bauer, M. E., Burk, T. E., Ek, A. R., Coppin, P. R., Lime, S. D., Walsh, T. A., Walters, D. K., Befort, W., and Heinzen, D. H., 1994, Satellite inventory of Minnesota forest resources. Photogrammetric Engineering and Remote Sensing, 60, 287-298.

Beaubien, J., Cihlar, J., Simard, G., and Latifovic, R., 1999, Land cover from multiple Thematic Mapper scenes using a new enhancement-classification methodology. Journal of Geophysical Research, in press.

Beaubien, J., and Simard, G., 1993, Méthodologie de classification des données AVHRR pour la surveillance du couvert végétal. Proceedings of the 16th Canadian Remote Sensing Symposium, Sherbrooke, Québec, 7-10 June 1993 (Québec: Canadian Remote Sensing Society), pp. 597-603.

Bischof, H., and LEONARDis, A., 1998, Finding optimal neural networks for land use classification. IEEE Transactions on Geoscience and Remote Sensing, 36, 337-341.

Brown, J. F., Loveland, T. R., Merchant, J. W., Reed, B. C., and Ohlen, D. O., 1993, Using multisource data in global land cover characterization: concepts, requirements and methods. Photogrammetric Engineering and Remote Sensing, 59, 977-987.

Carpenter, G. A. Gjaja, M. N., Gopal, S., and Woodcock, C. E., 1997, ART neural networks for remote sensing: vegetation classification from Landsat TM and terrain data. IEEE Transactions on Geoscience and Remote Sensing, 35, 308-325.

Chavez, P., 1988, An improved dark-object subtraction technique for atmospheric scattering correction of multispectral data. Remote Sensing of Environment, 24, 459-479.

Chavez, P., 1989, Radiometric calibration of Landsat Thematic Mapper multispectral images. Photogrammetric Engineering and Remote Sensing, 55, 1285-1294.

Chen, J. M., and Cihlar, J., 1997, A hotspot function in a simple bidirectional reflectance model for satellite applications. Journal of Geophysical Research, 102, 25907-25913.

Chuvieco, E., and Congalton, R. G., 1988, Using cluster analysis to improve the selection of training statistics in classifying remotely sensed data. Photogrammetric Engineering and Remote Sensing, 54, 1275-1281.

Cinlar, J., 1996, Identification of contaminated pixels in AVHRR composite images for studies of land biosphere. Remote Sensing of Environment, 56, 149-163.

Cihlar, J., and Beaubien, J., 1998, Land Cover of Canada 1995 Version 1.1. Digital data set documentation, Natural Resources Canada, Ottawa, Ontario.

Cihlar, J., Beaubien, J., Xiao, Q., Chen, J., and Li, Z., 1997a, Land cover of the BOREAS Region from AVHRR and Landsat data. Canadian Journal of Remote Sensing, 23, $163-175$.

Cihlar, J., Chen, J., Li, Z., Huang, F., Latifovic, R., and Dixon, R., 1998a, Can interannual land surface signal be discerned in composite AVHRR data? Journal of Geophysical Research-Atmospheres, 103, 23163-23172.

Cihlar, J., and Howarth, J., 1994, Detection and removal of cloud contamination from AVHRR composite images. IEEE Transactions on Geoscience and Remote Sensing, 32, 427-437.

Cihlar, J., Latifovic, R., Chen, J., Beaubien, J., and Li, Z., 1998b, Selecting high resolution sample in land cover studies. Part 1: algorithm. Remote Sensing of Environment, in press.

Cihlar, J., Latifovic, R., Chen, J., Beaubien, J., Li, Z., and Magnussen, S., 1998c, Selecting high resolution sample in land cover studies. Part 2: application to estimating land cover composition. Remote Sensing of Environment, in press.

Cihlar, J., Latifovic, R., Chen, J., and Li, Z., 1999, Near-real time detection of contaminated pixels in AVHRR composites. Canadian Journal of Remote Sensing, 25, 160-170.

Cihlar, J., Ly, H., Li, Z., Chen, J., Pokrant, H., and Huang, F., 1997b, Multitemporal, multichannel AVHRR data sets for land biosphere studies: artifacts and corrections. Remote Sensing of Environment, 60, 35-57.

Cihlar, J., Ly, H., and XIAO, Q., 1996, Land cover classification with AVHRR multichannel composites in northern environments. Remote Sensing of Environment, 58, 36-51. 
Cihlar, J., ManaK, D., and D'Iorio, M., 1994a, Evaluation of compositing algorithms for AVHRR data over land. IEEE Transactions for Geoscience and Remote Sensing, 32, 427-437.

Cihlar, J., Manak, D., and Voisin, N., 1994b, AVHRR bidirectional reflectance effects and compositing. Remote Sensing of Environment, 48, 77-88.

Cihlar, J., Xiao, Q., Beaubien, J., Fung, K., and Latifovic, R., 1998e, Classification by Progressive Generalization: a new automated methodology for remote sensing multichannel data. International Journal of Remote Sensing, 19, 2685-2704.

Colwell, R. N., (editor) 1960, Manual for Photographic Interpretation (Washington, D.C.: The American Society of Photogrammetry).

Congalton, R. G., 1991, A review of assessing the accuracy of classifications of remotely sensed data. Remote Sensing of Environment, 37, 35-46.

Congalton, R. G., 1996, Accuracy assessment: a critical component of land cover mapping. In Gap Analysis: A Landscape Approach to Biodiversity Planning, edited by J. M. Scott, T. H. Tear and F. Davis (Bethesda, Maryland: American Society for Photogrammetry and Remote Sensing), pp. 119-131.

Cracknell, A. P., and Paithoonwattanakij, K., 1989, Pixel and sub-pixel accuracy in geometrical image correction of AVHRR imagery. International Journal of Remote Sensing, 10, 661-667.

De Boissezon, H., Gonzales, G., Pus, B., and Sharman, M., 1993, Rapid estimation of crop acreage and production at a European scale using high resolution imagery-operational review. Proceedings of the International Symposium 'Operationalization of Remote Sensing', ITC Enschede, The Netherlands, pp. 94-105.

DeFries, R., Hansen, M., Steininger, M., Dubayah, R., Sohlberg, R., and Townshend, J., 1997, Subpixel forest cover in central Africa from multisensor, multitemporal data. Remote Sensing of Environment, 60, 228-246.

DeFries, R. S., Hansen, M., and Townshend, J. R. G., 1995, Global discrimination of land cover types from metrics derived from AVHRR Pathfinder data. Remote Sensing of Environment, 54, 209-222.

DeFries, R. S., Hansen, M., Townshend, J. R. G., and Sohlberg, R., 1998, Global land cover classification at $8 \mathrm{~km}$ spatial resolution: the use of training data derived from Landsat imagery in decision tree classifiers. International Journal of Remote Sensing, 19, 3141-3168.

DeFries, R.S., and Townshend, J. R. G., 1994, NDVI-derived land cover classification at global scales. International Journal of Remote Sensing, 15, 3567-3586.

Dickinson, R. E., Henderson-Sellers, A., Kennedy, P. J., and Wilson, M. F., 1986, Biosphereatmosphere transfer scheme (BATS) for the NCAR community climate model. NCAR Technical Note NCAR/TN275 + STR, Boulder, CO, USA.

Driese, K. L., Reiners, W. A., Merrill, E. H., and Gerow, K. G., 1997, A digital land cover map of Wyoming, USA: a tool for vegetation analysis. Journal of Vegetation Science, 8, 133-146.

Dubayah, R., Blair, B., Bufton, J., Clarke, D., JàJà, J., Knox, R., Luthcke, S., Prince, S., and Weishampel, J., 1997, The Vegetation Canopy Lidar mission. Presented at the Symposium on Land Satellite Information in the Next Decade II, American Society for Photogrammetry and Remote Sensing, Washington, D.C. $<$ http://www.inform.umd.edu/Geography/vcl/ >

Edwards, T. C. Jr, Moisen, G. G., and Cutler, D. R., 1998, Assessing map accuracy in a remotely sensed, ecoregion-scale cover map. Remote Sensing of Environment, 63, 73-83.

Eidenshink, J. C., and FAundeEn, J. L., 1994, The $1 \mathrm{~km}$ AVHRR global land data set: first stages in implementation. International Journal of Remote Sensing, 15, 3443-3462.

Elvidge, C. D., Yuan, D., Weerackoon, R. D., and Lunetta, R. S., 1995, Relative radiometric normalization of Landsat Multispectral Scanner (MSS) data using an automatic scattergram-controlled regression. Photogrammetric Engineering and Remote Sensing, 61, 1255-1260.

EMERY, W. J., Brown, J., and NowAK, Z. P., 1989, AVHRR image navigation: summary and review. Photogrammetric Engineering and Remote Sensing, 55, 1175-1183.

Eva, H. D., Malingreau, J. P., Gregoire, J. M., Belward, A. S., and Mutlow, C. T., 1998, The advance of burnt areas in Central Africa as detected by ATSR-1. International Journal of Remote Sensing, 19, 1635-1637. 
Foody, G. M., 1996, Approaches for the production and evaluation of fuzzy land cover classifications from remotely-sensed data. International Journal of Remote Sensing, 17, $1317-1340$.

Foody, G. M., 1998, Sharpening fuzzy classification output to refine the representation of sub-pixel land cover distribution. International Journal of Remote Sensing, 19, 25932599.

Foody, G. M., Lucas, R. M., Curran, P. J., and Honzak, M., 1997, Non-linear mixture modeling without end-members using an artificial neural network. International Journal of Remote Sensing, 18, 937-953.

FRIEDMANN, D. E., 1981, Operational resampling for correcting images to a geocoded format. Proceedings of the Fifteenth International Symposium on Remote Sensing of Environment, Ann Arbor, MI (Environmental Research Institute of Michigan), pp. 195-199.

GCOS, 1997, GCOS/GTOS plan for terrestrial climate-related observations. Report GCOS32, WMO/TD-No. 796, World Meteorological Organization.

Gong, P., Marceau, D. J., and Howarth, P. J., 1992, A comparison of spatial feature extraction algorithms for land-use classification with SPOT HRV data. Remote Sensing of Environment, 40, 137-151.

Goward, S. N., Markham, B., Dye, D. G., Dulaney, W., and Yang, J., 1991, Normalized difference vegetation index measurements from the Advanced Very High Resolution Radiometer. Remote Sensing of Environment, 35, 257-277.

Guindon, B., 1995, Utilization of Landsat Pathfinder data for the creation of large area mosaics. Proceedings of the 1995 ACSM/ASPRS Conference, Charlotte, NC (American Society of Photogrammetry and Remote Sensing), Volume 2, pp. 144-153.

GuINDON, B., 1997, Assessing the radiometric fidelity of high resolution image mosaics. ISPRS Journal of Photogrammetry and Remote Sensing, 52, 229-243.

Gutman, G. G., 1994, Normalization of multi-annual global AVHRR reflectance data over land surfaces to common sun-target-sensor geometry. Advances in Space Research, 14, (1) $121-(1) 124$.

Gutman, G. G., Ignatov, A. M., and Olson, S., 1994, Towards better quality of AVHRR composite images over land: reduction of cloud contamination. Remote Sensing of Environment, 50, 134-148.

Hammond, T. O., and Verbyla, D. L., 1996, Optimistic bias in classification accuracy assessment. International Journal of Remote Sensing, 17, 1261-1266.

Hansen, M. C., DeFries, R. S., Townshend, J. R. G., and Sohlberg, R., 2000, Global land cover classification at $1 \mathrm{~km}$ spatial resolution using a classification tree approach. International Journal of Remote Sensing, 21, 1331-1364.

Hansen, M., Dubayah, R., and DeFries, R., 1996, Classification trees: an alternative to traditional land cover classifiers. International Journal of Remote Sensing, 17, 10751081.

Holben, B., 1986, Characteristics of maximum-value composite images from temporal AVHRR data. International Journal of Remote Sensing, 7, 1417-1434.

Homer, C. G., Ramsey, R. D., Edwards, T. C. Jr, and Falconer, A., 1997, Landscape covertype modeling using a multi-scene Thematic Mapper mosaic. Photogrammetric Engineering and Remote Sensing, 63, 59-67.

Hord, R. M., and Brooner, W., 1976, Land-use map accuracy criteria. Photogrammetric Engineering and Remote Sensing, 42, 671-677.

IGBP, 1990, The International Geosphere-Biosphere Programme: a study of global change. The initial core projects. IGBP Report \#12, Stockholm, Sweden.

Iverson, L. R., Cook, E. A., and Graham, R. L., 1994, Regional forest cover estimation via remote sensing: the calibration center concept. Landscape Ecology, 9, 159-174.

James, M. E., and Kalluri, S. N. V., 1994, The Pathfinder AVHRR land data set: an improved coarse resolution data set for terrestrial monitoring. International Journal of Remote Sensing, 15, 3347-364.

JENNINGS, M. D., 1995, Gap analysis today: a confluence of biology, ecology, and geography for management of biological resources. Wildlife Society Bulletin, 23, 658-662.

Kalkhan, M. A., Reich, R. M., and Stohlgren, T. J., 1998, Assessing the accuracy of Landsat Thematic Mapper classification using double sampling. International Journal of Remote Sensing, 19, 2049-2060. 
Kartikeyan, B., Sarkar, A., and Majumder, K. L., 1998, A segmentation approach to classification of remote sensing imagery. International Journal of Remote Sensing, 19, 1695-1709.

Kelly, P. M., and White, J. M., 1993, Preprocessing remotely-sensed data for efficient analysis and classification. Knowledge-based systems in aerospace and industry: applications of artificial intelligence. Proceedings SPIE, 24-30.

Laporte, N. T., Goetz, S. J., Justice, C. O., and Heinecke, M., 1998, A new land cover map of central Africa derived from multi-resolution, multi-temporal AVHRR data. International Journal of Remote Sensing, 19, 3537-3550.

LARK, R. M., 1995a, A reappraisal of unsupervised classification, I: correspondence between spectral and conceptual classes. International Journal of Remote Sensing, 16, 1425-1423.

LARK, R. M., 1995b, A reappraisal of unsupervised classification, II: optimal adjustment of the map legend and a neighbourhood approach for mapping legend units. International Journal of Remote Sensing, 16, 1445-1460.

LEROY, M., 1994, Compositing reflectance measured from space for vegetation monitoring. Proceedings of the Sixth International Symposium on Physical Measurements and Signatures in Remote Sensing, Val d'Isere, France, 17-21 January 1994, pp. 21-32.

Li, Z., Cihlar, J., Zhang, X., Moreau, L., and Ly, H., 1996, The bidirectional effects of AVHRR measurements over boreal regions. IEEE Transactions on Geoscience and Remote Sensing, 34, 1308-1322.

LI, Z., and Leighton, H. G., 1992, Narrowband to broadband conversion with spatially autocorrelated reflectance measurements. Journal of Applied Meteorology, 31, 421-432.

LiLlesAnD, T. M., 1996, A protocol for satellite-based land cover classification in the Upper Midwest. In Gap Analysis: A Landscape Approach to Biodiversity Planning, edited by J. M. Scott, T. H. Tear and F. Davis (Bethesda, Maryland: American Society for Photogrammetry and Remote Sensing), pp. 103-118.

Liu, J., Chen, J. M., Cihlar, J., and Park, W., 1997, A process-based boreal ecosystem productivity simulator using remote sensing inputs. Remote Sensing of Environment, 62, 158-175.

Loveland, T. R., and Belward, A. S., 1997, The IGBP-DIS global $1 \mathrm{~km}$ land cover dataset, DISCover: first results. International Journal of Remote Sensing, 18, 3289-3295.

Loveland, T. R., Merchant, J. W., Brown, J. F., Ohlen, D. O., Reed, B. C., Olson, P., and Hutchinson, J., 1995, Seasonal land-cover regions of the United States. Annals of the Association of American Geographers, 85, 339-355.

Loveland, T. R., Merchant, J. W., Ohlen, D. O., and Brown, J. F., 1991, Development of a land-cover characteristics database for the conterminous U.S. Photogrammetric Engineering and Remote Sensing, 57, 1453-1463.

Loveland, T. R., Reed, B. C., Brown, J. F., Ohlen, D. O., Zhu, Z., Yang, L., and Merchant, J. W., 2000, Development of a global land cover characteristics database and IGBP DISCover from 1-km AVHRR data. International Journal of Remote Sensing, 21, $1303-1330$.

Los, S. O., Justice, C. O., and Tucker, C. J., 1994, A global $1^{\circ}$ by $1^{\circ}$ NDVI data set for climate studies derived from the GIMMS continental NDVI data. International Journal of Remote Sensing, 15, 3493-3518.

Magnussen, S., 1997, Calibrating photo-interpreted forest cover types and relative species compositions to their ground expectations. Canadian Journal of Forest Research, 27, 491-500.

Mannan, B., Roy, J., and Ray, A. K., 1998, Fuzzy ARTMAP supervised classification of multi-spectral remotely-sensed images. International Journal of Remote Sensing, 19, $767-774$.

Martonchik, J. V., Diner, D. J., Pinty, B., Verstraete, M. M., Myneni, R. B., Knyazikhin, Y., and Gordon, H. R., 1998, Determination of land and ocean reflective, radiative and biophysical properties using multiangle imaging. IEEE Transactions on Geoscience and Remote Sensing, 36, 1266-1281.

Mathews, E., 1983, Global vegetation and land use: new high resolution data bases for climate studies. Journal of Climate and Applied Meteorology, 22, 474-487.

Mayaux, P., Achard, F., and Malingreau, J.-P., 1998, Global tropical forest area measurements derived from coarse resolution satellite imagery: a comparison with other approaches. Environmental Conservation, 25, 37-52. 
Mayaux, P., and Lambin, E., 1995, Estimation of tropical forest area from coarse spatial resolution data: a two-step correction function for proportional errors due to spatial aggregation. Remote Sensing of Environment, 53, 1-16.

Mayaux, P., and Lambin, E. F., 1997, Tropical forest area measured from global land-cover classifications: inverse calibration models based on spatial textures. Remote Sensing of Environment, 59, 29-43.

Moody, A., and Woodcock, C. E., 1996, Calibration-based models for correction of area estimates derived from coarse resolution land-cover data. Remote Sensing of Environment, 58, 225-241.

NASA, 1982, LANDSAT-4 World Reference System (WRS) User Guide. National Aeronautics and Space Administration, Goddard Space Flight Center, Greenbelt, MD, USA.

Nishihama, M., Wolfe, R. E., Solomon, D., Patt, F., Blanchette, J., Fleig, A., and Masuoka, E., 1997, MODIS Level 1A earth location: Algorithm Theoretical Basis Document. Report SDST-092, Laboratory for Terrestrial Physics, NASA Goddard Space Flight Center, Greenbelt, MD, USA.

Olson, J. S., Watts, J., and Allison, L., 1983, Carbon in live vegetation of major world ecosystems. Report W-7405-ENG-26, U.S. Department of Energy, Oak Ridge National Laboratory, USA.

O’Neill, R. V., Krummel, J. R., Gardner, R. H., Sugihara, G., Jackson, B., DeAngelis, D. L., Milne, B. T., Turner, M. G., Zygmunt, B., Christensen, S. W., Dale, V. H., and GrahaM, R. L., 1988, Indices of landscape pattern. Landscape Ecology, 1, 153-162.

PCI, 1998, ORTHOENGINE. PCI Software Package, PCI Inc., Toronto, ON, Canada.

Pokrant, H., 1991, Land cover map of Canada derived from AVHRR images. Manitoba Remote Sensing Centre, Winnipeg, MB, Canada.

QI, J., and Kerr, Y., 1994, On current compositing algorithms. Proceedings of the Sixth International Symposium on Physical Measurements and Signatures in Remote Sensing, Val d'Isere, France, 17-21 January 1994, pp. 135-142.

RABBEN, E. L., 1960, Fundamentals of photo interpretation. In Manual of Photographic Interpretation, edited by R. N. Colwell (Washington, D.C.: The American Society of Photogrammetry), pp. 99-168.

Robertson, B., Erickson, A., Friedel, J., Guindon, B., Fisher, T., Brown, R., Teillet, P., D'Iorio, M., Cihlar, J., and Sancz, A., 1992, GEOCOMP, A NOAA AVHRR Geocoding and Compositing System. Proceedings of the ISPRS Conference, Commission 2, Washington, D.C., pp. 223-228.

Rosenfield, G. H., and FitzPatrick-Lins, K., 1986, A coefficient of agreement as a measure of thematic classification accuracy. Photogrammetric Engineering and Remote Sensing, 52, 223-227.

Running, S. W., Justice, C. O., Salomonson, V., Hall, D., Barker, J., Kaufmann, Y. J., Strahler, A. H., Huette, A. R., Muller, J.-P., Vanderbilt, V., Wan, Z. M., Teillet, P., and CARneggie, D., 1994, Terrestrial remote sensing science and algorithms planned for EOS/MODIS. International Journal of Remote Sensing, 15, 3587-3620.

Running, S. W., Loveland, T. R., Pierce, L. L., Nemani, R. R., and Hunt, E. R. Jr, 1995, A remote sensing based vegetation classification logic for global land cover analysis. Remote Sensing of Environment, 51, 39-48.

SAINT, G., 1992, VEGETATION onboard SPOT 4: mission specifications. Report No. 92102, Laboratoire d'etudes et de recherches en teledetection spatiale, Toulouse, France.

Salomonson, V.V., Barnes, W. L., Maymon, P. W., Montgomery, H. E., and Ostrow, H., 1989, MODIS: advanced facility instrument for studies of the Earth as a system. IEEE Transactions on Geoscience and Remote Sensing, 27, 145-153.

Schott, J. R., Salvaggio, C., and VolchoK, W. J., 1988, Radiometric scene normalization using pseudoinvariant features. Remote Sensing of Environment, 26, 1-16.

Sellers, P. J., Los, S. O., Tucker, C. J., Justice, C. O., Dazlich, D. A., Collatz, J. A., and RANDALl, D. A., 1994, A global $1^{\circ}$ by $1^{\circ}$ NDVI data set for climate studies. Part 2: The generation of global fields of terrestrial biophysical parameters from the NDVI. International Journal of Remote Sensing, 15, 3519-3545.

Sellers, P. J., Randall, D. A., Collatz, G. J., Berry, J. A., Field, C. B., Dazlich, D. A., Zhang, C., Collelo, G. D., and Bounoua, L., 1996, A revised land surface parameterization (SiB2) for atmospheric GCMs - Part I-model formulation. Journal of Climate, 9, 676-705. 
Shimabukuro, Y. E., Mello, E. M. K., Moreira, J. C., and Duarte, V., 1997, Segmentacao e classificacao da imagem sombra do modelo de mistura para mapear desflorestamento na Amazona. Report INPE-6147-PUD/029, Instituto Nacional de Pesquisas Espacias, Sao Jose dos Campos, Brazil.

Staenz, K., Brown, R. J., and Teillet, P. M., 1984, Influence of the viewing geometry on vegetation measures. Proceedings of the 8th Canadian Symposium on Remote Sensing, Montreal, QUE, May 3-6 1984 (Canadian Remote Sensing Society), pp. 5-12.

Steyaert, L. T., Hall, F. G., and Loveland, T. R., 1997, Land cover mapping, fire regeneration, and scaling studies in the Canadian boreal forest with $1 \mathrm{~km}$ AVHRR and Landsat TM data. Journal of Geophysical Research, 102, 29581-29598.

Thomas, I. L., and McKallcock, G., 1984, Determining the confidence level for a classification. Photogrammetric Engineering and Remote Sensing, 50, 1491-1496.

Townshend, J. R. G., Justice, C. O., Skole, D., Malingreau, J.-P., Cihlar, J., Teillet, P., SAdowski, F., and Ruttenberg, S., 1994, The $1 \mathrm{~km}$ resolution global data set: needs of the International Geosphere - Biosphere Programme. International Journal of Remote Sensing, 15, 3417-3441.

VAN Der Meer, F., 1995, Spectral unmixing of Landsat Thematic Mapper data. International Journal of Remote Sensing, 16, 3189-3194.

Viovy, N., Arino, O., and Belward, A. S., 1992, The Best Index Slope Extraction (BISE): a method for reducing noise in NDVI time-series. International Journal of Remote Sensing, 13, 1585-1590.

Vogelmann, J. E., Sohl, T., and Howard, S. M., 1998, Regional characterization of land cover using multiple sources of data. Photogrammetric Engineering and Remote Sensing, 64, 45-57.

Walsh, T. A., and Burk, T. E., 1993, Calibration of satellite classifications of land area. Remote Sensing of Environment, 46, 281-290.

Wigmosta, M. S., Vail, L. W., and Lettenmaier, D. P., 1994, A distributed hydrologyvegetation model for complex terrain. Water Resources Research, 30, 1665-1679.

Wu, A., LI, Z., and Cihlar, J., 1995, Effects of land cover type and greenness on AVHRR bidirectional reflectances: analysis and removal. Journal of Geophysical Research, 100, 9179-9192.

Yool, S. R., 1998, Land cover classification in rugged areas using simulated moderateresolution remote sensor data and an artificial neural network. International Journal of Remote Sensing, 19, 85-96.

Yuan, D., and Elvidge, C. D., 1996, Comparison of relative radiometric normalization techniques. ISPRS Journal of Photogrammetry and Remote Sensing, 51, 117-126.

Zhu, Z., and Evans, D. L., 1994, U.S. forest types and predicted percent forest cover from AVHRR data. Photogrammetric Engineering and Remote Sensing, 60, 525-531. 